\title{
Altered Basolateral Amygdala Encoding in an Animal Model of Schizophrenia
}

\author{
(D)Alex Hernandez, ${ }^{5 \star}$ Amanda C. Burton, ${ }^{1,2 \star}$ Patricio 0’Donnell, ${ }^{5}$ Geoffrey Schoenbaum, $, 3,4,5$ and Matthew R. Roesch ${ }^{1,2}$ \\ ${ }^{1}$ Department of Psychology and ${ }^{2}$ Program in Neuroscience and Cognitive Science, University of Maryland, College Park, Maryland 20742, ${ }^{3}$ NIDA-IRP, \\ Baltimore, Maryland 21224, ${ }^{4}$ Solomon H. Snyder Department of Neuroscience, The Johns Hopkins University, Baltimore, Maryland 21287, and \\ ${ }^{5}$ Department of Anatomy and Neurobiology, University of Maryland School of Medicine, Baltimore, Maryland 21201
}

It has been proposed that schizophrenia results, in part, from the inappropriate or spurious attribution of salience to cues in the environment. We have recently reported neural correlates of salience in the basolateral amygdala (ABL) of rats during learning in an odor-guided discrimination task. Here we tested whether this dopamine-dependent salience signal is altered in rats with neonatal ventral hippocampal lesions (NVHLs), a rodent model of schizophrenia. We found that ABL signals related to violations in reward prediction were only mildly affected by NVHL; however, neurons in rats with NVHLs showed significantly stronger selectivity during odor sampling, particularly for the more salient large-reward cue. The elevated cue-evoked activity in NVHL rats was correlated with heightened orienting behavior and also with changes in firing to the shifts in reward, suggesting that it reflected abnormal signaling of the large rewardpredicting cue's salience. These results are broadly consistent with the proposal that schizophrenics suffer from enhanced signaling of salience.

Key words: amygdala; behavior; electrophysiology; rat; salience; schizophrenia

\section{Introduction}

Research on schizophrenia had traditionally focused on pathophysiology in PFC, a brain region critical for flexible decision making, working memory, cognitive flexibility, and reward processing (Carter et al., 1998; Ragozzino and Kesner, 1999; Ragozzino et al., 1999a, b; Manes et al., 2002; Harrison and Weinberger, 2005; Lewis et al., 2005; Gold et al., 2008; Rushworth and Behrens, 2008; Floresco et al., 2009; Stopper and Floresco, 2015). Patients with schizophrenia show loss of markers associated with GABA interneurons in PFC and reproduction of interneuron deficits in animals demonstrates changes in behaviors consistent with PFC dysfunction and schizophrenia (Benes and Berretta, 2001; Berretta et al., 2001; O'Donnell et al., 2002; Lipska et al., 2003, 2004; Spencer et al., 2003; Lewis et al., 2005; Cabungcal et al., 2006; Behrens et al., 2007; Hikida et al., 2007; Tseng and O'Donnell, 2007; Tseng et al., 2007, 2008; Lodge and Grace, 2009; Lodge et al., 2009). For example, after neonatal ventral hippocampal lesions (NVHLs) in rats, PFC is hyperactive and taskrelated field potential oscillations are reduced, consistent with

\footnotetext{
Received Dec. 16, 2014; revised Feb. 20, 2015; accepted March 16, 2015.

Author contributions: A.H., P.O., G.S., and M.R.R. designed research; A.H., P.O., G.S., and M.R.R. performed research; A.H., A.C.B., P.O., G.S., and M.R.R. analyzed data; A.H., A.C.B., P.O., G.S., and M.R.R. wrote the paper.

This work was supported by funding from the National Institute on Drug Abuse (G.S.) and R01DA031695 (M.R.R.).

*A.H. and A.C.B. contributed equally to this paper.

The authors declare no competing financial interests.

Correspondence should be addressed to Matthew Ryan Roesch, 1147 Biology-Psychology Building, University of Maryland, College Park, MD 20742. E-mail: mroesch@umd.edu.

P. O'Donnell's present address: Psychiatry and Behavioral Disorders, Neuroscience Research Unit, Pfizer, Inc., 610 Main Street, Cambridge, MA 02139.

DOI:10.1523/JNEUROSCI.5096-14.2015

Copyright $\odot 2015$ the authors $\quad 0270-6474 / 15 / 356394-07 \$ 15.00 / 0$
}

deficits in interneuron function (Gruber et al., 2010). These changes in neural activity are accompanied by a lost ability to track rewarding outcomes. These deficits were improved by reducing PFC excitability, suggesting that dysfunction in PFC was the primary cause of the abnormal behavior (Gruber et al., 2010).

Notably PFC receives heavy input from the basolateral amygdala (ABL), and we have recently found that signaling in the ABL provides a dopamine-dependent Pearce-Hall salience signal (PH; Pearce and Hall, 1980; Pearce et al., 1982) in the same setting in which NVHL rats appear to inappropriately track rewarding outcomes (Roesch et al., 2010a). Similar correlates have also been reported in amygdala during reversal learning in humans (Li et al., 2011). This is relevant to schizophrenia because recent theories have suggested that the appropriate "attribution of salience" might underlie many of the deficits observed in schizophrenia (Baruch et al., 1988; Jones et al., 1992; Grecksch et al., 1999; Kapur, 2003; Kapur et al., 2005; Ouhaz et al., 2014).

Here we tested whether these neural correlates of salience in ABL might be enhanced in NVHL rats. We recorded neurons in NVHL and sham rats performing a simple odor-based choice task in which they had to detect errors in reward prediction across blocks of trials to appropriately guide their behavior. As described previously, NVHL rats exhibited a reduced ability to track rewarding outcomes when contingencies changed (Gruber et al., 2010). We found that ABL signals related to violations in reward prediction were only mildly affected by NVHL; however, neurons in rats with NVHLs showed significantly stronger selectivity during odor sampling, particularly for the more salient large-reward cue. The elevated cue-evoked activity in NVHL rats was correlated with heightened orienting behavior and also with changes in firing to the unexpected shifts in reward, suggesting that it re- 
flected abnormal signaling of the large reward-predicting cue's salience.

\section{Materials and Methods}

Subjects. All experiments were performed according to United States Public Health Service Guide for the Care and Use of Laboratory Animals and were approved by the University of Maryland Institutional Animal Care and Use Committee. Procedures for neonatal lesions follow previously described methods (Lipska, 2004; Gruber et al., 2010). On P7-P8, male Long-Evans pups born on site were bilaterally injected with $0.3 \mu \mathrm{l}$ of either aCSF (sham) or ibotenic acid (0.3 $\mu \mathrm{g}$; NVHL) in the ventral hippocampus ( $3 \mathrm{~mm}$ posterior, $\pm 3.5 \mathrm{~mm}$ lateral, and $5 \mathrm{~mm}$ ventral to bregma). A total of five NVHL and three sham rats were used in this study; additional data from 12 controls run in other studies were also included. Rats were group housed until the start of behavioral training at $\mathrm{P} 41$.

Surgical procedures and histology. Surgical procedures followed guidelines for aseptic technique. Electrodes were manufactured and implanted as in prior recording experiments. Rats had a drivable bundle of $1025 \mu \mathrm{m}$ diameter FeNiCr wires (Stablohm 675; California Fine Wire) chronically implanted in the left hemisphere dorsal to either ABL $(n=7 ; 3.0 \mathrm{~mm}$ posterior to bregma, $5.0 \mathrm{~mm}$ laterally, and $7.5 \mathrm{~mm}$ ventral to the brain surface). Immediately before implantation, these wires were freshly cut with surgical scissors to extend $\sim 1 \mathrm{~mm}$ beyond the cannula and electroplated with platinum $\left(\mathrm{H}_{2} \mathrm{PtCl}_{6}\right.$; Sigma-Aldrich $)$ to an impedance of $\sim 300 \mathrm{kOhm}$. Cephalexin ( $15 \mathrm{mg} / \mathrm{kg}$, p.o.) was administered twice daily for 2 weeks postoperatively to prevent infection. At the end of recording, the final electrode position was marked by passing a $15 \mu \mathrm{A}$ current through each electrode. Single-unit activity observed on recordable channels often ceased after passing through the ventral extent of ABL ( $\sim 8.6$ ventral to brain surface). Rats were perfused, and their brains removed and processed for histology using standard techniques to confirm final recording locations.

Behavioral task. Recording was conducted in aluminum chambers $\sim 18$ in. on each side with sloping walls narrowing to an area of $12 \times 12$ in. at the bottom. A central odor port was located above two adjacent fluid wells on a panel in the right wall of each chamber. Two lights were located above the panel. The odor port was connected to an air-flow dilution olfactometer to allow the rapid delivery of olfactory cues. Task control was implemented via computer. Port entry and licking were monitored by disruption of photobeams. The basic design of a trial is illustrated in Figure 1. Trials were signaled by illumination of the panel lights inside the box. When these lights were on, nose poke into the odor port resulted in delivery of the odor cue to a small hemicylinder located behind this opening. One of three different odors was delivered to the port on each trial, in a pseudorandom order. At odor offset, the rat had $3 \mathrm{~s}$ to make a response at one of the two fluid wells located below the port. One odor (Verbena Oliffac) instructed the rat to go to the left to get reward, a second odor (Camekol DH) instructed the rat to go to the right to get reward, and a third odor (Cedryl Acet Trubek) indicated that the rat could obtain reward at either well. Odors were presented in a pseudorandom sequence such that the free-choice odor was presented on $7 / 20$ trials and the left/right odors were presented in equal numbers $( \pm 1$ over 250 trials). In addition, the same odor could be presented on no more than three consecutive trials. Odor identity did not change over the course of the experiment. Once the rats were shaped to perform this basic task, we introduced blocks in which we manipulated the size of the reward delivered at a given side. Once the rats were able to maintain accurate responding through these manipulations, we began recording sessions. For recording, one well was designated as large (two boli separated by $500 \mathrm{~ms}$ ) and the other as small reward (one boli). In the second block of trials these contingencies were switched. At least 60 trials per block were collected for each neuron. Rats were water deprived ( $\sim 30 \mathrm{~min}$ of free water per day) with free access on weekends.

Single-unit recording. Wires were screened for activity daily; if no activity was detected, the rat was removed, and the electrode assembly was advanced $40 \mu \mathrm{m}$ or $80 \mu \mathrm{m}$. Otherwise active wires were selected to be recorded, a session was conducted, and the electrode was advanced at the end of the session. Neural activity was recorded using two identical
Plexon Multichannel Acquisition Processor systems, interfaced with odor-discrimination training chambers. Signals from the electrode wires were amplified $20 \times$ by an op-amp headstage (Plexon; HST/8o50-G20GR), located on the electrode array. Immediately outside the training chamber, the signals were passed through a differential pre-amplifier (Plexon; PBX2/16sp-r-G50/16fp-G50), where the single-unit signals were amplified $50 \times$ and filtered at $150-9000 \mathrm{~Hz}$. The single-unit signals were then sent to the Multichannel Acquisition Processor box, where they were further filtered at $250-8000 \mathrm{~Hz}$, digitized at $40 \mathrm{kHz}$, and amplified at $1-32 \times$. Waveforms ( $>2.5: 1$ signal-to-noise) were extracted from active channels and recorded to disk by an associated workstation with event time stamps from the behavior computer.

Data analysis. Units were sorted using Offline Sorter software from Plexon, using a template-matching algorithm. Sorted files were then processed in NeuroExplorer to extract unit time stamps and relevant event markers. These data were subsequently analyzed in MATLAB. Our analysis focused on activity 1000 ms after reward delivery (reward epoch; Figs. 2, 3) and during odor sampling (odor onset to odor port exit, odor epoch; Fig. 4). Wilcoxon tests were used to measure significant shifts from zero in distribution plots and at the population level $(p<0.05)$. $T$ tests or ANOVAs were used to measure within cell differences in firing rate because they were normally distributed. Pearson $\chi^{2}$ tests $(p<0.05)$ were used to compare the proportions of neurons.

\section{Results}

ABL neurons in NVHL and control rats were recorded in a choice task (Fig. 1a). On each trial, rats responded to one of two adjacent wells after sampling an odor at a central port. Rats were trained to respond to three different odor cues: one that signaled reward in the right well (forced choice), a second that signaled reward in the left well (forced choice), and a third that signaled reward in either well (free choice). At the start of different blocks of trials, we manipulated the size of the reward, thereby increasing or decreasing its value unexpectedly.

Consistent with previous work, we found that NVHL rats were slightly worse at tracking the better outcome during freechoice trials (Fig. $1 b$; $t$ test; $t_{(273)}=5.2, p<0.05$ ). Although NVHL rats' performance on free-choice trials was worse, all behavioral measures (percentage choice, percentage correct, and reaction time) clearly indicated that they were aware of reward contingencies in that they chose large reward over small reward on free-choice trials. In addition, rats in both groups were faster and more accurate on large versus small reward forced-choice trials (Fig. $1 c, d ; t$ test; $t_{(100)} s>9.6, p s<0.05$ ). Thus, like control rats, NVHL rats perceived the differently sized rewards as having different values.

In addition to these measures, we also examined how quickly rats oriented to the odor port upon illumination of house lights. Speed of orienting to the odor port precedes knowledge of the upcoming reward and thus cannot reflect the motivational value of the upcoming reward; instead this measure, like changes in other measures of orienting (Kaye and Pearce, 1984; Pearce et al., 1988; Swan and Pearce, 1988), may reflect error-driven increases in the processing of trial events (e.g., cues and/or reward), which may include increased attention or reception to odor cues when expectancy errors need to be resolved. This behavior might be considered an investigatory reflex to allow for recovery of habituation when learned contingencies are violated or re-engagement of instrumental task performance when responding can no longer be based on previous reward contingencies or stimulusresponse habits that might have developed over the course of the trial block. Accordingly, rats showed faster orienting at the start of blocks when the value of the expected rewards changed, responding significantly faster during early trials (first five trials) compared with later trials (last five trials; Fig. 1e). Both groups 
a

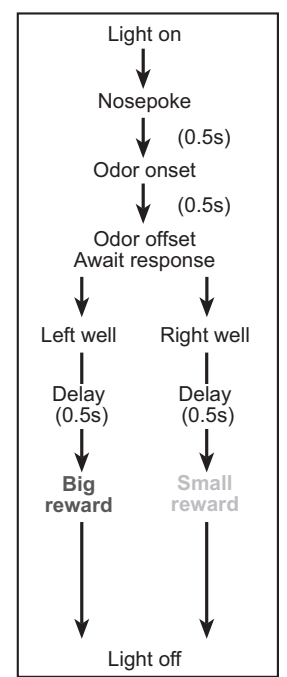

b

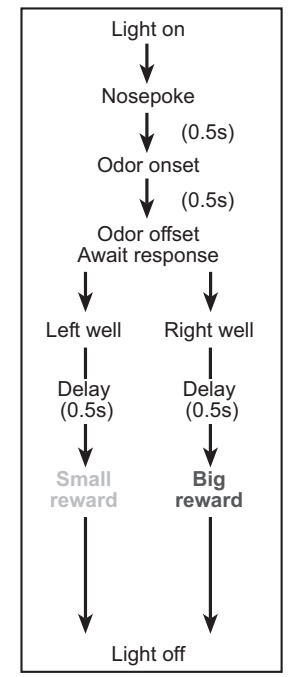

C
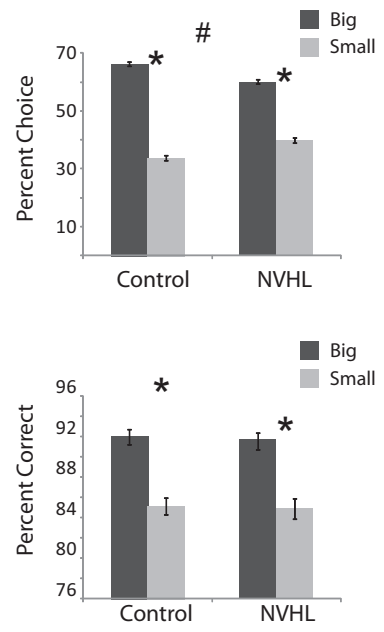

d

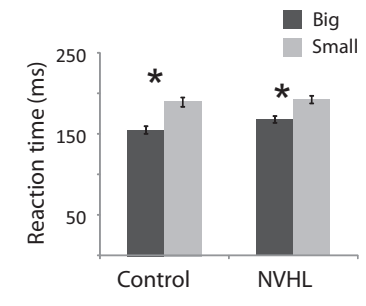

e

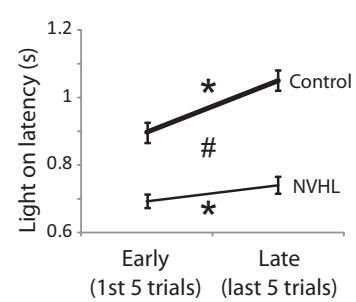

Figure 1. a, Sequence of task events. Upon house-light illumination, rats nose poked into a central odor port. After $500 \mathrm{~ms}$, one of three odors was presented. One odor signaled forced-choice left, another odor signaled forced-choice right, and a third odor signaled free choice. After the $500 \mathrm{~ms}$ presentation of the odor, rats had $3 \mathrm{~s}$ to respond to one of the fluid wells. After fluid well entry the rats were required to wait in the well until reward was delivered. The size of the reward (large $=2$ boli or small $=1$ bolus) associated with left and right fluid wells varied from block to block. Trial blocks consisted of at least 60 rewarded trials. See Materials and Methods for more detail. $\boldsymbol{b}-\boldsymbol{d}$, The height of each bar indicates the percentage choice on free-choice trials $(\boldsymbol{b})$, and the percentage correct (c) and reaction time ( $\boldsymbol{d}$; odor offset to odor port exit) on large-reward (dark gray) and small-reward (light gray) trials for control and NVHL. $\boldsymbol{e}$, Latency to nose poke after onset of house lights during the first and last five trials in each block for NVHL (thin) and control (thick) rats. Analyzed behavior comes from recording sessions with reward-response cells from which neural analysis was performed. Asterisks indicate planned comparisons revealing statistically significant differences ( $t$ test, $p<0.05$ ). Error bars indicate SEs. \#, Indicates main effect of group (NVHL vs control) in the ANOVA $(p<0.05)$.

showed this effect (control: $t_{(173)}=5.4$, $p<0.05$; lesion: $\left.t_{(100)}=2.7, p=0.05\right)$; however, NVHL rats were much faster than controls overall $\left(t_{(273)}=6.7, p<\right.$ 0.05 ), and showed less of a decline in speed across the trial block $\left(t_{(273)}=2.7\right.$, $p<0.05)$.

Against this backdrop, we recorded 367 neurons in NVHL rats and 693 neurons in controls (Fig. 2a,b). We focused our analysis on changes in reward-evoked firing, which we have previously shown correlates with salience or attentional shifts after violations in reward predictions (Roesch et al., 2010a, 2012a; Esber et al., 2012). This signal is specifically evident in reward-responsive neurons, thus we began by screening for these cells in control and NVHL rats, comparing activity during reward to activity at baseline. The proportion of neurons that increased firing to reward delivery ( $1 \mathrm{~s}$ after reward compared with $1 \mathrm{~s}$ before nose poke) was not significantly different between groups [Fig. $2 c ; 174(25 \%)$ vs $101(28 \%) ; \chi^{2}=$ $0.006, p=0.94]$; however, baseline firing of these neurons was significantly reduced in NVHL rats (2.9 vs 2.1 spikes/s; Wilcoxon; $p<0.05$ ).

Next, we asked how many of these neurons were selective for reward size. Consistent with reports that ABL encodes value (Nishijo et al., 1988; Schoenbaum et al., 1998; Sugase-Miyamoto and Richmond, 2005; Belova et al., 2007, 2008; Tye a

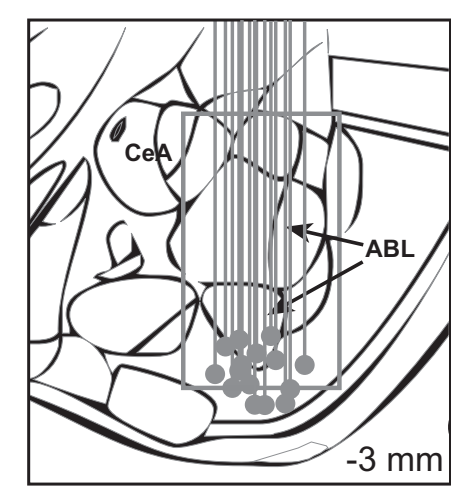

C d

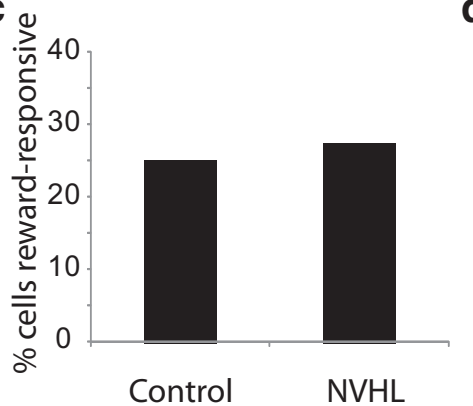

b

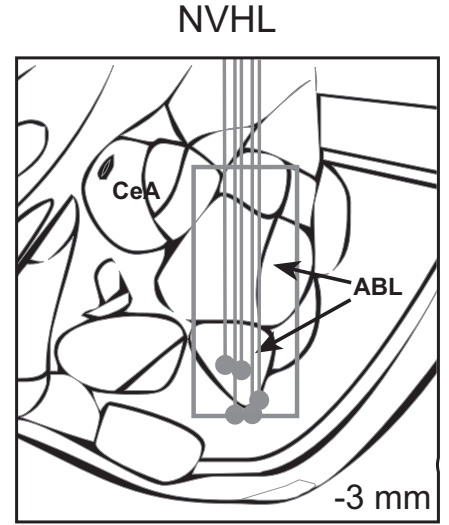

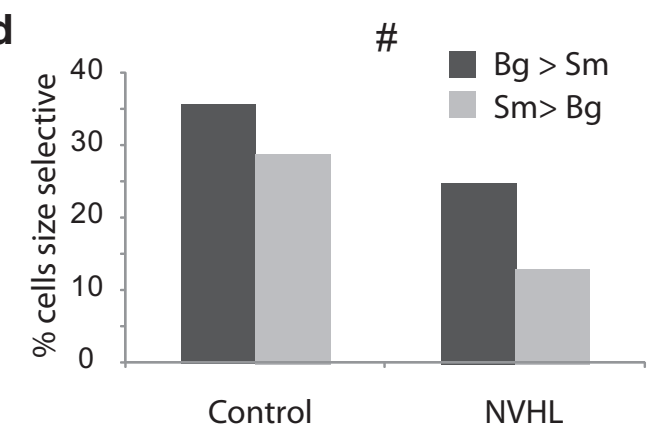

Figure 2. Outcome selectivity in ABL is reduced in NVHL rats. $\boldsymbol{a}, \boldsymbol{b}$, Recording sites for each rat verified by histology. Gray dot marks the bottom of electrodes. Box represents the extent of the recordings in which single units were collected and considered to be in ABL based on histology and the recording location at which activity was no longer observed. $c$, The percentage of rewardresponsive neurons in ABL (higher firing $1 \mathrm{~s}$ after reward compared with baseline; $t$ test; $p<0.05$ ) was not significantly different between control and NVHL rats $\left(\chi^{2}\right)$. $\boldsymbol{d}$, Height of each bar indicates the percentage of neurons that showed a significant effect of reward size during the $1 \mathrm{~s}$ after reward delivery, \#, Indicates main effect of group (NVHL vs control) in the ANOVA $(p<0.05)$. Bg, big; sm, small; CeA, central amygdala. 

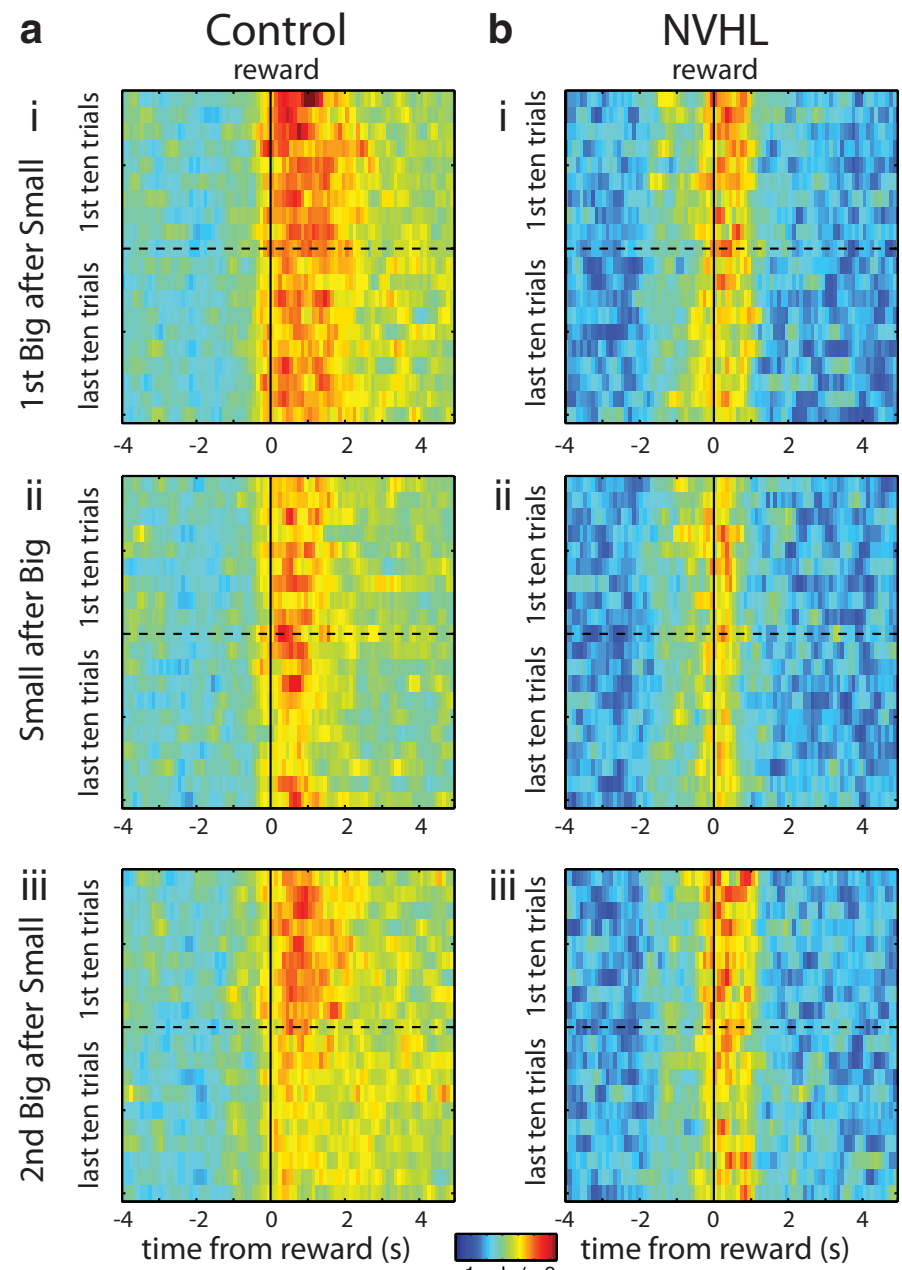
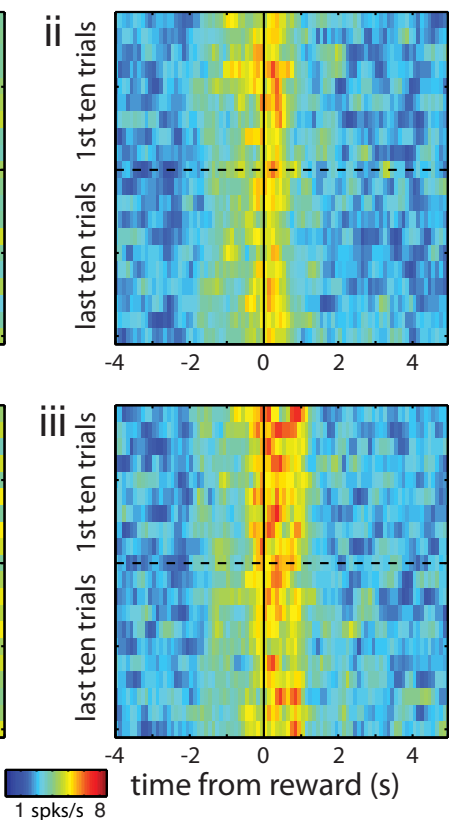

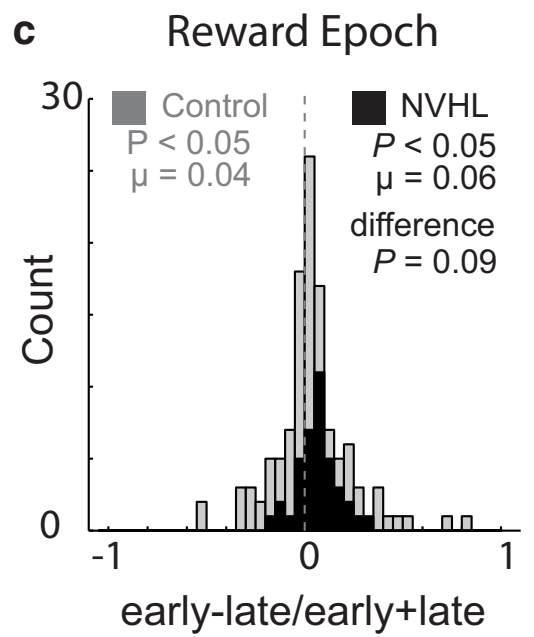

Figure 3. $\quad \boldsymbol{a}, \boldsymbol{b}$, Average firing over reward-selective neurons from both control ( $n=117$ ) and NVHL ( $n=39)$ groups, respectively. Heat plots representing activity early (first 10 trials) and late (last 10 trials) for large and small reward. ai and bi and aiii and biiiare large-reward trials that happened earlier (first size block) and later (second size block) in the block sequence. Both follow blocks during which a small reward was delivered in that well. aii and $\boldsymbol{b i i}$ represent activity during small-reward delivery after a block of trials during which large reward was delivered (ai, bi). $\mathbf{c}$, distribution plots showing normalized contrasts in activity (early - late/early + late) for each neuron in response to changes in reward contingencies during the reward epoch. Black and gray represent NVHL and control groups, respectively. Pvalues represent the significance of Wilcoxon tests used to determine significance of shifts in the distributions from zero and the "difference" between distributions obtained from NVHL (black) and control (gray) rats.

et al., 2008; Fontanini et al., 2009), neurons in both groups exhibited significant differential firing $(t$ test; $p<0.05)$ based on the size of the reward (ANOVA); however, NVHL rats had significantly fewer size-sensitive neurons (Fig. $2 d ; \chi^{2}=5.2, p=0.02$; see also heat plots in Fig. 3 for effects of big vs small and overall baseline changes). Thus lesioned rats had similar numbers of reward-responsive neurons when compared with controls, but these neurons fired more slowly and were less likely to be selective between large and small rewards.

Reward-selective ABL neurons in both control and lesion groups also showed transient increases in firing at the beginning of each trial block, consistent with registration of salient reward shifts as previously reported (Roesch et al., 2010a, 2012b). As before, these increases were apparent over several trials and occurred when reward was delivered or omitted. This is illustrated in Figure 3, $a$ and $b$, which plots the average firing over rewardselective neurons from both control and NVHL groups, respectively. These effects were significant across the population as quantified in the distribution plots showing the contrast in activity (early vs late) for each neuron in response to changes in reward contingencies during the reward epoch (Fig. $3 c$; early - late/early
+ late). These distributions were shifted significantly above zero for both control (gray) and lesioned (black) groups, indicating higher firing immediately after a change in reward than later after learning (Wilcoxon; $p s<0.05$ ). There was a trend toward heightened signaling in the NVHL group; however, it did not reach significance (Fig. $3 c$; Wilcoxon; $p=0.09$ ). Thus ABL neurons in both groups increased firing when reward predictions were violated.

Next, we examined the activity of these neurons during odor sampling (odor epoch; Fig. 4, gray bar). The odor epoch encompassed time between the onset of the odor and the initiation of the response. The rapid orientation of NVHL rats to the odor port suggested that they showed stronger error-driven increases in the processing of trial events including presentation of the odor at the start of the trial (Fig. $4 a, b$ ). Activity in ABL in NVHL rats, which showed less selectivity based on reward size at the time of reward, showed more selectivity based on reward size at the time of odor sampling (odor epoch), firing significantly more strongly for cues that predicted large over small reward after learning (Fig. $4 b$; late; gray vs black solid lines; Wilcoxon, $p<0.05$ ). This effect was significant across the population of single neurons as quantified 
a

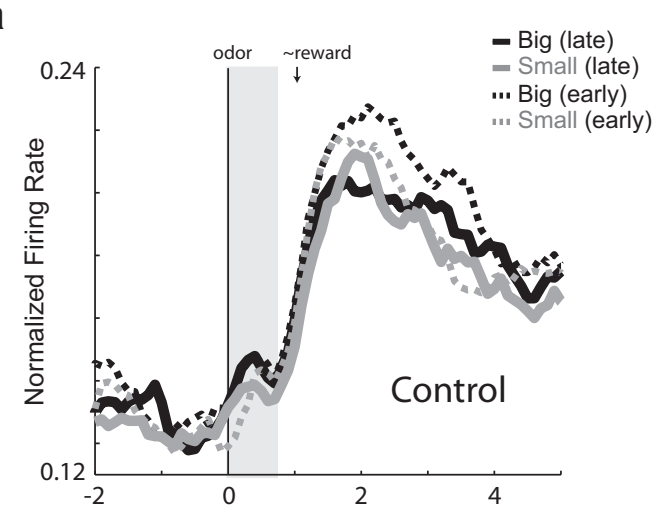

b
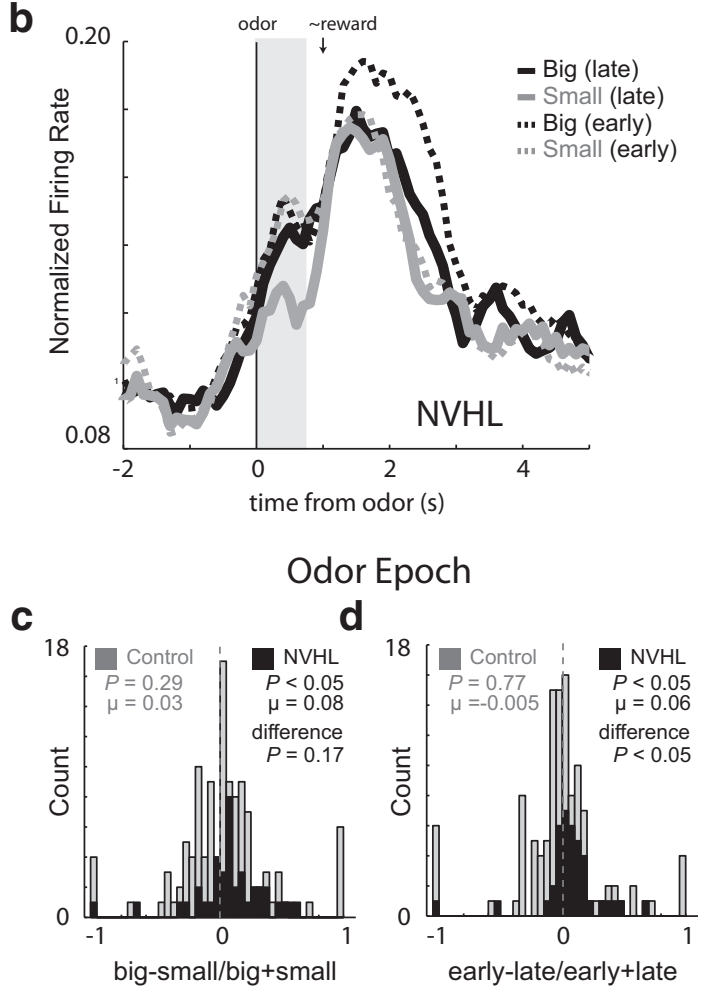

e

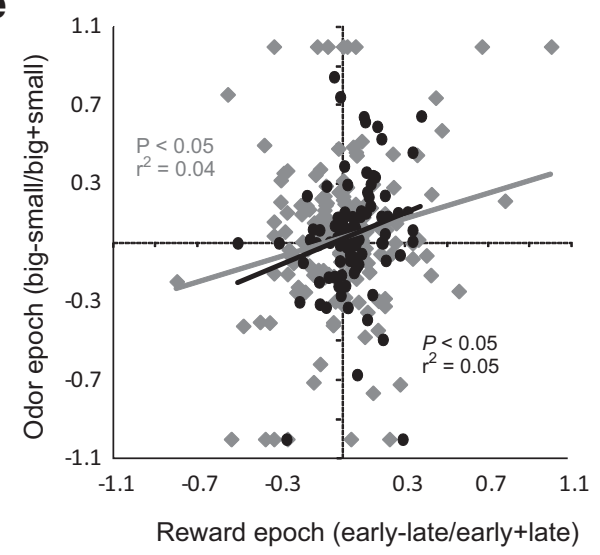

Figure 4. $\quad \boldsymbol{a}, \boldsymbol{b}$, Average normalized firing rate for all reward-selective neurons aligned to odor onset for controls ( $n=117$ cells; 15 rats) and NVHL groups ( $n=39$ cells; 5 rats). Black, big; gray, small; dashed, first five trials (early); solid, last five trials (late). Vertical gray bar indicates odor epoch used in analysis. c, Distribution plots showing the normalized contrast in activity (large vs small) for each neuron during the odor epoch. The average firing for each trial type over all these neurons is plotted over time for control and NVHL groups in $\boldsymbol{a}$ and $\boldsymbol{b}$, respectively. $\boldsymbol{d}$, Distribution plots showing the normalized contrast in activity (early vs late) for each neuron in in the distribution plots showing the contrast in activity (large vs small) for each neuron (Fig. $4 c$, black bars; big - small/big + small). This distribution was shifted significantly above zero, indicating higher firing for cues that predicted larger reward (Fig. $4 c$; Wilcoxon; $p<0.05$ ) and was positively correlated with attentional changes observed during the reward epoch $\left(r^{2}=0.05, p<\right.$ 0.05 ; Fig. $4 e$ ), demonstrating neurons that showed increases during errors in reward prediction (Fig. 3c) exhibited cue selectivity during odor sampling (Fig. 4c).

Interestingly, development of this signal reflected the selective reduction in firing for cues that predicted the small reward with learning (Fig. $4 b$; odor epoch: vertical gray bar; gray dashed vs solid lines; Wilcoxon; $p<0.05$ ). This effect was significant across the population as quantified in the distribution plots showing the contrast in activity (early vs late) for each neuron in response to changes in reward contingencies (Fig. $4 d$; black bars). This distribution was shifted significantly above zero for NVHL rats, indicating higher firing during odor sampling immediately after a change in reward contingencies (Fig. $4 d$; Wilcoxon; $p<0.05$ ).

Neither size selectivity nor elevating firing during learning (early) was observed in control animal's average across the population during the odor epoch (Fig. $4 a$, vertical gray bar; Wilcoxon; $p s>0.28$ ) or in the distributions of single neurons (Fig. $4 c, d$, gray bars; Wilcoxon; $p s>0.29$ ). Although differences in size selectivity between the two groups only approached significance (Fig. $4 c$; Wilcoxon; $p=0.17$ ), distributions representing elevated firing during early trials was significantly more positive in NVHL compared with control rats (Fig. $4 d$; Wilcoxon; $p<0.05$ ).

\section{Discussion}

Previously we have shown that activity in ABL is selective for differently valued outcomes and is modulated by errors in reward prediction consistent with PH (Pearce and Hall, 1980; Pearce et al., 1982) attention signals thought to be critical in reinforcement learning (Roesch et al., 2010a, b, 2012a; Kashtelyan et al., 2012). This work is consistent with a number of studies showing modulation of firing in ABL during unexpected reward delivery and omission, and the predictability of appetitive and aversive events (Belova et al., 2007; Johansen et al., 2010; Tye et al., 2010). According to the $\mathrm{PH}$ model, the amount of attention received by a cue is inversely related to how well the cue has predicted past reward. Hence, a cue that has reliably signaled reward will receive less attention than a cue that predicts uncertain reward. Contrary to the hypothesis that deficits in schizophrenia might reflect elevated or spurious allocation of attention or salience, this signal was relatively unaffected by neonatal ventral hippocampal lesions during unexpected reward delivery. This suggests that if such an effect occurs in schizophrenia it is either not well modeled by NVHLs or occurs due to changes in other areas. One candidate might be the ACC; we and others have found attention-related activity prominently in ACC, and this is a prefrontal area affected in NVHL (Bryden et al., 2011; Roesch et al., 2012a).

response to changes in reward contingencies during the odor epoch (odor onset to odor port exit; gray vertical bar). Black and gray represent NVHL and control groups, respectively. $\boldsymbol{e}$, Correlation between odor selectivity (big - small/big + small) during the odor epoch and changes in firing between early and late trials (early - late/early + late) during the reward epoch for NVHL (black) and control (gray) rats over all recorded neurons. P values represent the significance of Wilcoxon tests used to determine significance of shifts in the distributions from zero and the "difference" between distributions obtained from NVHL (black) and control (gray) rats. 
However, NVHL rats did show altered signaling in ABL. Although NVHL rats had equivalent numbers of reward-responsive (i.e., firing different from baseline) neurons, they did exhibit a significant reduction in the number of reward-selective (firing difference between large- and small-reward) neurons, which might contribute to poor choice performance in this task. In contrast, during odor sampling, we found that ABL neurons that carried attentional signals also fired strongly to odor cues at the start of trial blocks and became selective over the course of learning. This effect was not observed in controls, and could reflect elevated attention to salient cues that was not significant during delivery of outcomes. Certainly the NVHL rats exhibited behavioral measures - changes in orienting to the odor ports- consistent with elevated attention leading into the odor-sampling period. Note, faster orienting to the odor port cannot simply reflect overspeeding of behavior because reaction time (motor response to odors) did not significantly differ between the two groups.

We have already shown that neonatal hippocampal lesions make PFC hyperactive and attenuate task-related field potential oscillations (Gruber et al., 2010). These changes in neural activity are clearly related to the lost ability to track rewarding outcomes during performance of the same reward-guided decision-making task used here. Although our previous results suggested that the primary cause of the abnormal behavior was dysfunction in PFC, as evidenced by recovery of function after pharmacologically reducing PFC excitability, these data would also be consistent with a role for other regions. The results here suggest that ABL might also play a role in this abnormal behavior.

The fact that ABL is affected in NVHL animals is not surprising considering it receives direct projections from ventral hippocampus, which gates excitatory input (O'Donnell and Grace, 1995; Wright et al., 1996; Pitkänen et al., 2000). However, it is still not yet clear how altered firing in ABL might impact ventral hippocampus and PFC across development in NVHL rats or if these changes in ABL firing might reflect NVHL-induced changes in PFC function. What is clear is that PFC output is noisy and disorganized in NVHL rats, which might lead to the inability of PFC to flip between previously acquired associations when contingencies change, resulting in poor choice performance. This might impact processing in $\mathrm{ABL}$, as well as other brain systems in the circuit thought to be disrupted in NHVL and schizophrenia.

In general, overactivity and increased signaling in response to salient cues in the NVHL rats is broadly consistent with reports of attentional deficits in settings like latent inhibition in schizophrenic patients and NVHL rats, as well as with recent proposals that aberrant attribution of motivational salience is a key determinant of many symptoms of schizophrenia (Baruch et al., 1988; Jones et al., 1992; Grecksch et al., 1999; Kapur, 2003; Kapur et al., 2005; Ouhaz et al., 2014). The motivational salience hypothesis suggests that the dopamine system mediates the conversion of neutral representations of external stimuli to ones that convey their learned value. Notably salience signals in ABL are dopamine dependent (Esber et al., 2012), providing one possible mechanism for this to occur. This attribution of motivational salience is thought to enhance attention and drive learning, and might lead to misrepresentations of the external world that underlie psychosis, hallucinations, and delusions (Kapur, 2003; Kapur et al., 2005).

\section{References}

Baruch I, Hemsley DR, Gray JA (1988) Differential performance of acute and chronic schizophrenics in a latent inhibition task. J Nerv Ment Dis 176:598-606. CrossRef Medline
Behrens MM, Ali SS, Dao DN, Lucero J, Shekhtman G, Quick KL, Dugan LL (2007) Ketamine-induced loss of phenotype of fast-spiking interneurons is mediated by NADPH-oxidase. Science 318:1645-1647. CrossRef Medline

Belova MA, Paton JJ, Morrison SE, Salzman CD (2007) Expectation modulates neural responses to pleasant and aversive stimuli in primate amygdala. Neuron 55:970-984. CrossRef Medline

Belova MA, Paton JJ, Salzman CD (2008) Moment-to-moment tracking of state value in the amygdala. J Neurosci 28:10023-10030. CrossRef Medline

Benes FM, Berretta S (2001) GABAergic interneurons: implications for understanding schizophrenia and bipolar disorder. Neuropsychopharmacology 25:1-27. CrossRef Medline

Berretta S, Munno DW, Benes FM (2001) Amygdalar activation alters the hippocampal GABA system: "partial" modelling for postmortem changes in schizophrenia. J Comp Neurol 431:129-138. CrossRef Medline

Bryden DW, Johnson EE, Tobia SC, Kashtelyan V, Roesch MR (2011) Attention for learning signals in anterior cingulate cortex. J Neurosci 31: 18266-18274. CrossRef Medline

Cabungcal JH, Nicolas D, Kraftsik R, Cuénod M, Do KQ, Hornung JP (2006) Glutathione deficit during development induces anomalies in the rat anterior cingulate GABAergic neurons: relevance to schizophrenia. Neurobiol Dis 22:624-637. CrossRef Medline

Carter CS, Perlstein W, Ganguli R, Brar J, Mintun M, Cohen JD (1998) Functional hypofrontality and working memory dysfunction in schizophrenia. Am J Psychiatry 155:1285-1287. CrossRef Medline

Esber GR, Roesch MR, Bali S, Trageser J, Bissonette GB, Puche AC, Holland PC, Schoenbaum G (2012) Attention-related Pearce-Kaye-Hall signals in basolateral amygdala require the midbrain dopaminergic system. Biol Psychiatry 72:1012-1019. CrossRef Medline

Floresco SB, Zhang Y, Enomoto T (2009) Neural circuits subserving behavioral flexibility and their relevance to schizophrenia. Behav Brain Res 204:396-409. CrossRef Medline

Fontanini A, Grossman SE, Figueroa JA, Katz DB (2009) Distinct subtypes of basolateral amygdala neurons reflect palatability and reward. J Neurosci 29:2486-2495. CrossRef Medline

Gold JM, Waltz JA, Prentice KJ, Morris SE, Heerey EA (2008) Reward processing in schizophrenia: a deficit in the representation of value. Schizophr Bull 34:835-847. CrossRef Medline

Grecksch G, Bernstein HG, Becker A, Höllt V, Bogerts B (1999) Disruption of latent inhibition in rats with postnatal hippocampal lesions. Neuropsychopharmacology 20:525-532. CrossRef Medline

Gruber AJ, Calhoon GG, Shusterman I, Schoenbaum G, Roesch MR, O’Donnell P (2010) More is less: a disinhibited prefrontal cortex impairs cognitive flexibility. J Neurosci 30:17102-17110. CrossRef Medline

Harrison PJ, Weinberger DR (2005) Schizophrenia genes, gene expression, and neuropathology: on the matter of their convergence. Mol Psychiatry 10:40-68; image 5. CrossRef Medline

Hikida T, Jaaro-Peled H, Seshadri S, Oishi K, Hookway C, Kong S, Wu D, Xue R, Andradé M, Tankou S, Mori S, Gallagher M, Ishizuka K, Pletnikov M, Kida S, Sawa A (2007) Dominant-negative DISC1 transgenic mice display schizophrenia-associated phenotypes detected by measures translatable to humans. Proc Natl Acad Sci U S A 104:14501-14506. CrossRef Medline

Johansen JP, Tarpley JW, LeDoux JE, Blair HT (2010) Neural substrates for expectation-modulated fear learning in the amygdala and periaqueductal gray. Nat Neurosci 13:979-986. CrossRef Medline

Jones SH, Gray JA, Hemsley DR (1992) Loss of the Kamin blocking effect in acute but not chronic schizophrenics. Biol Psychiatry 32:739-755. CrossRef Medline

Kapur S (2003) Psychosis as a state of aberrant salience: a framework linking biology, phenomenology, and pharmacology in schizophrenia. Am J Psychiatry 160:13-23. CrossRef Medline

Kapur S, Mizrahi R, Li M (2005) From dopamine to salience to psychosislinking biology, pharmacology and phenomenology of psychosis. Schizophr Res 79:59-68. CrossRef Medline

Kashtelyan V, Tobia SC, Burton AC, Bryden DW, Roesch MR (2012) Basolateral amygdala encodes upcoming errors but not response conflict. Eur J Neurosci 35:952-959. CrossRef Medline

Kaye H, Pearce JM (1984) The strength of the orienting response during Pavlovian conditioning. J Exp Psychol Anim Behav Process 10:90-109. CrossRef Medline 
Lewis DA, Hashimoto T, Volk DW (2005) Cortical inhibitory neurons and schizophrenia. Nat Rev Neurosci 6:312-324. CrossRef Medline

Li J, Schiller D, Schoenbaum G, Phelps EA, Daw ND (2011) Differential roles of human striatum and amygdala in associative learning. Nat Neurosci 14:1250-1252. CrossRef Medline

Lipska BK (2004) Using animal models to test a neurodevelopmental hypothesis of schizophrenia. J Psychiatry Neurosci 29:282-286. Medline

Lipska BK, Lerman DN, Khaing ZZ, Weickert CS, Weinberger DR (2003) Gene expression in dopamine and GABA systems in an animal model of schizophrenia: effects of antipsychotic drugs. Eur J Neurosci 18:391-402. CrossRef Medline

Lodge DJ, Grace AA (2009) Gestational methylazoxymethanol acetate administration: a developmental disruption model of schizophrenia. Behav Brain Res 204:306-312. CrossRef Medline

Lodge DJ, Behrens MM, Grace AA (2009) A loss of parvalbumin-containing interneurons is associated with diminished oscillatory activity in an animal model of schizophrenia. J Neurosci 29:2344-2354. CrossRef Medline

Manes F, Sahakian B, Clark L, Rogers R, Antoun N, Aitken M, Robbins T (2002) Decision-making processes following damage to the prefrontal cortex. Brain 125:624-639. CrossRef Medline

Nishijo H, Ono T, Nishino H (1988) Single neuron responses in alert monkey during complex sensory stimulation with affective significance. J Neurosci 8:3570-3583. Medline

O’Donnell P, Grace AA (1995) Synaptic interactions among excitatory afferents to nucleus accumbens neurons: hippocampal gating of prefrontal cortical input. J Neurosci 15:3622-3639. Medline

O’Donnell P, Lewis BL, Weinberger DR, Lipska BK (2002) Neonatal hippocampal damage alters electrophysiological properties of prefrontal cortical neurons in adult rats. Cereb Cortex 12:975-982. CrossRef Medline

Ouhaz Z, Ba-M'hamed S, Bennis M (2014) Haloperidol treatment at preexposure phase reduces the disturbance of latent inhibition in rats with neonatal ventral hippocampus lesions. C R Biol 337:561-570. CrossRef Medline

Pearce JM, Hall G (1980) A model for Pavlovian learning: variations in the effectiveness of conditioned but not of unconditioned stimuli. Psychol Rev 87:532-552. CrossRef Medline

Pearce JM, Kaye H, Hall G (1982) Predictive accuracy and stimulus associability: development of a model for Pavlovian learning. In: Quantitative analyses of behavior (Commons ML, Herrnstein RJ, Wagner AR, eds), pp 241-255. Cambridge, MA: Ballinger.

Pearce JM, Wilson P, Kaye H (1988) The influence of predictive accuracy on serial conditioning in the rat. Q J Exp Psychol 40B:181-198.

Pitkänen A, Pikkarainen M, Nurminen N, Ylinen A (2000) Reciprocal connections between the amygdala and the hippocampal formation, perirhinal cortex, and postrhinal cortex in rat. A review. Ann N Y Acad Sci 911:369-391. CrossRef Medline

Ragozzino ME, Kesner RP (1999) The role of the agranular insular cortex in working memory for food reward value and allocentric space in rats. Behav Brain Res 98:103-112. CrossRef Medline

Ragozzino ME, Detrick S, Kesner RP (1999a) Involvement of the prelimbicinfralimbic areas of the rodent prefrontal cortex in behavioral flexibility for place and response learning. J Neurosci 19:4585-4594. Medline

Ragozzino ME, Wilcox C, Raso M, Kesner RP (1999b) Involvement of ro- dent prefrontal cortex subregions in strategy switching. Behav Neurosci 113:32-41. CrossRef Medline

Roesch MR, Calu DJ, Esber GR, Schoenbaum G (2010a) Neural correlates of variations in event processing during learning in basolateral amygdala. J Neurosci 30:2464-2471. CrossRef Medline

Roesch MR, Calu DJ, Esber GR, Schoenbaum G (2010b) All that glitters. dissociating attention and outcome expectancy from prediction errors signals. J Neurophysiol 104:587-595. CrossRef Medline

Roesch MR, Esber GR, Li J, Daw ND, Schoenbaum G (2012a) Surprise! Neural correlates of Pearce-Hall and Rescorla-Wagner coexist within the brain. Eur J Neurosci 35:1190-1200. CrossRef Medline

Roesch MR, Esber GR, Bryden DW, Cerri DH, Haney ZR, Schoenbaum G (2012b) Normal aging alters learning and attention-related teaching signals in basolateral amygdala. J Neurosci 32:13137-13144. CrossRef Medline

Rushworth MF, Behrens TE (2008) Choice, uncertainty and value in prefrontal and cingulate cortex. Nat Neurosci 11:389-397. CrossRef Medline

Schoenbaum G, Chiba AA, Gallagher M (1998) Orbitofrontal cortex and basolateral amygdala encode expected outcomes during learning. Nat Neurosci 1:155-159. CrossRef Medline

Spencer KM, Nestor PG, Niznikiewicz MA, Salisbury DF, Shenton ME, McCarley RW (2003) Abnormal neural synchrony in schizophrenia. J Neurosci 23:7407-7411. Medline

Stopper CM, Floresco SB (2015) Dopaminergic circuitry and risk/reward decision making: implications for schizophrenia. Schizophr Bull 41:9-14. CrossRef Medline

Sugase-Miyamoto Y, Richmond BJ (2005) Neuronal signals in the monkey basolateral amygdala during reward schedules. J Neurosci 25:1107111083. CrossRef Medline

Swan JA, Pearce JM (1988) The orienting response as an index of stimulus associability in rats. J Exp Psychol Anim Behav Process 14:292-301. CrossRef Medline

Tseng KY, O’Donnell P (2007) Dopamine modulation of prefrontal cortical interneurons changes during adolescence. Cereb Cortex 17:1235-1240. CrossRef Medline

Tseng KY, Lewis BL, Lipska BK, O’Donnell P (2007) Post-pubertal disruption of medial prefrontal cortical dopamine-glutamate interactions in a developmental animal model of schizophrenia. Biol Psychiatry 62:730 738. CrossRef Medline

Tseng KY, Lewis BL, Hashimoto T, Sesack SR, Kloc M, Lewis DA, O’Donnell P (2008) A neonatal ventral hippocampal lesion causes functional deficits in adult prefrontal cortical interneurons. J Neurosci 28:12691-12699. CrossRef Medline

Tye KM, Stuber GD, de Ridder B, Bonci A, Janak PH (2008) Rapid strengthening of thalamo-amygdala synapses mediates cue-reward learning. Nature 453:1253-1257. CrossRef Medline

Tye KM, Cone JJ, Schairer WW, Janak PH (2010) Amygdala neural encoding of the absence of reward during extinction. J Neurosci 30:116-125. CrossRef Medline

Wright CI, Beijer AV, Groenewegen HJ (1996) Basal amygdaloid complex afferents to the rat nucleus accumbens are compartmentally organized. J Neurosci 16:1877-1893. Medline 